\title{
ANALYSIS ON EVOLUTION AND CHARACTERISTICS OF CARBON EMISSIONS OF SHANXI PROVINCE, CHINA
}

\author{
XU, L. N. ${ }^{1,2,3,4,5}-$ SHI, X. J. ${ }^{5}-$ FAN, C. Y. $.^{1,2^{*}}-$ CHEN, S. Z. ${ }^{2}-$ YANG, X. F. ${ }^{1,2}-$ LIU, H. ${ }^{4,6}$ \\ ${ }^{1}$ Energy Economics and Environmental Policy Research Centre, Datong University \\ Datong, Shanxi 037009, China (e-mail: xulina1999@163.com) \\ ${ }^{2}$ Business School, Datong University, Datong, Shanxi 037009, China \\ ${ }^{3}$ Datong Macroeconomic Research Center, Datong, Shanxi 037009, China \\ ${ }^{4}$ School of Environment, Tsinghua University, Beijing 100084, China \\ ${ }^{5}$ National Energy Conservation Centre, Beijing 100045, China \\ ${ }^{6}$ Regional Economic Teaching and Research Department Sichuan Administration College \\ Chengdu, Sichuan 610071, China \\ *Corresponding author \\ e-mail:dtfcy@sohu.com \\ (Received 27 $7^{\text {th }}$ Feb 2019; accepted $3^{\text {rd }}$ May 2019)
}

\begin{abstract}
The paper calculates carbon emissions, and analyses relationship among economic growth, industrial structure, energy structure and carbon emissions using environmental quality equation based on the terminal energy consumption data in 1990-2017 based on Shanxi province in China. The results show that economic development is the main positive driving factor of carbon emissions, industrial structure has an inverted $\mathrm{u}$-shaped curve related with the carbon emissions and there is not a high linear correlation between energy structure and carbon emissions. Finally, some suggestions are proposed to reduce carbon emissions. The energy-intensive provinces should adjust industrial structure and pay more attention to the improvement of technologies, at the same time, should keep the population rate not increasing rapidly and energy structure not degenerating.
\end{abstract}

Keywords: carbon emissions; economic growth; industrial structure; energy structure; diversity factors; environmental quality equation

\section{Introduction}

As the biggest carbon emission increment country in the world, China is facing more and more international pressure on carbon emission reduction. As a responsible big country, the Chinese government, in accordance with China's national conditions, stage of development, sustainable development strategy and international responsibilities, has set the goal of self-action to reach the peak of carbon emissions by 2030 and reach the peak as soon as possible. In China, the implementation of energy-saving target responsibility system and the provincial-level decomposition of energy-saving targets require provinces to find out the evolution law of carbon emissions in accordance with their own natural and geographical conditions, resource endowment constraints, economic development models and economic development stages, based on which, to formulate reasonable emission reduction policies, and to achieve the decomposition goals. Rational emission reduction policies promote the smooth completion of the overall emission reduction targets. On the one hand, Energy-intensive provinces need to provide energy for China's development. On the other hand, they have great pressure on 
emissions, which has become a bottleneck for China to achieve the overall emission reduction goals. Therefore, it is of great practical significance to study the evolution of carbon emissions in energy-intensive provinces, find out the inherent mechanism of carbon emissions growth, and formulate reasonable emission reduction paths for specific provinces, so as to achieve the overall emission reduction goals in China.

\section{Review of literature}

In recent years, the growth of carbon emissions has been a hot topic both at home and abroad, and has made great progress. The existing research is mainly as follows, one aspect is the relationship between carbon emissions and the level of economic development and energy consumption. For example, Qi et al. (2015) selected six provinces in central China as the research object and used a variety of econometric analysis methods to study the relationship between economic growth and carbon emissions. Gao et al. (2017) discussed the possibility of the existence of environmental Kuznets curve and the existence of inflection point between carbon emission and economic growth in urban agricultural sector. Gao (2017) empirically analyzed the relationship between the relationship between energy consumption, carbon emissions and economic growth in Beijing Tianjin and Hebei region. Another aspect is to explore the driving forces of carbon emissions, and analyze the influencing factors of carbon emissions. Such as Chen et al. (2012), he analyzed the driving forces of carbon emissions from the theoretical and empirical level. Zhao and Yang (2012) used the factor analyzing method to study the driving force of China's carbon emissions. Xu et al. (2013) explored the driving force of carbon emissions in resource-based provinces combining with the PATH-STIRPA model. Song and Xu (2011), Wu et al. (2014), Li et al. (2015), Wang and Xie (2015), Ma et al. (2017), Zhou and Mao (2017), Yuan et al. (2017) analyzed the influencing factors of carbon emissions in China's cities and towns, China's provinces, China's power sector, China's industrial sector, China's export implied carbon emissions, China's provincial transport sector and China's provincial agricultural sector. Another aspect is the analysis of carbon emission forecasts. Such as Chi (2007), Huang et al. (2010), Liu (2011), Mirzaei and Bekri (2017), Wang et al. (2017) they used linear regression methods, ARIMA models, Logistic curves, and system dynamics methods to investigate and study issues related to predict carbon emissions in different regions combined with regression analysis methods.

At present, there are not many researches on the evolution of carbon emissions in China. Liu et al. (2013) used the dynamic distribution analysis method (MEDD) to empirically analyze the dynamic distribution and evolution of China's carbon emission intensity. Hu et al. (2016) selected panel data from 30 provinces and municipalities in China from 1997 to 2012 to analyze the evolution trend of carbon emission intensity in China and the regional differences. Tian et al. (2014) and Gao et al. (2017) analyzed the evolution trend of carbon emissions in China's agricultural sector and regional agricultural sector respectively. Sun et al. (2011) and Liang and Li (2014) explored the evolution characteristics of carbon emissions in the Bohai rim and Shandong province. Most of the existing research only selecting a certain industry in China as a whole sample, there are less research on the evolution of carbon emissions. Therefore, the author chose energy-intensive provinces as the research object, constructed the coefficient of diversification of industrial structure, the coefficient of diversification of energy consumption results, studied the evolution law of carbon emissions with the aid of environmental-quality equation and environmental Kuznets curve, and put forward 
practical policy suggestions for carbon emission reduction to provides policy reference and decision-making basis for the realization of carbon emission reduction goal in energy-intensive provinces.

\section{Estimation of total carbon emission}

\section{Calculation method of carbon emission}

According to the fourth assessment from IPCC (Intergovernmental Panel on Climate Change) (Lin and Liu, 2010; Lin and Huang, 2011; China National Development and Reform Commission, 2012), the carbon emissions calculated in this section are mainly carbon emissions caused by fossil energy consumption. Shanxi Province in China, a large coal resource province, is chosen as the representative of energy intensive provinces. Carbon emissions are estimated by the method from Lin and Liu (2010).

$$
C=\sum_{i} C_{i}=\sum_{i} E_{i} \times \alpha_{i} \times f_{i}
$$

Among the equation (1), $\mathrm{C}$ is total carbon emission, $\mathrm{C}_{\mathrm{i}}$ is carbon emissions from category $\mathrm{i}$ energy, $\mathrm{E}_{\mathrm{i}}$ is the category $\mathrm{i}$ energy consumption, $a_{i}$ is the conversion coefficient of standard coal of the category $i$ energy consumption, $f_{i}$ is the carbon emission coefficient of the category i energy.

\section{Data sources}

The study period was selected from 1990 to 2017, and all the energy data came from the Shanxi statistical yearbook (1991-2018). The final energy consumption is calculated based on the total conversion of physical consumption. In this paper, all the value calculation, was calculated setting 1952 as a benchmark year for the reduction, because the year of 1952 was setting as a base period which value was 100 in the statistical yearbook. In addition, this author estimated the end of fossil energy consumption according to the standard amount of carbon emissions, not calculating the carbon emissions from the energy losses generated during the process of conversion, transportation and distribution. The energy conversion coefficient was calculated by Appendix 4 of China Energy Statistics Yearbook (2018). The emission coefficients of coal, coke and natural gas was calculated by the carbon emission inventory published by IPCC. The numbers are $0.7559,0.8550,0.4483$ in turn. The oil carbon emission coefficient (Song, 2012) comes from the data published by the Energy Research Institute of the National Development and Reform Commission, the number is 0.5825.

\section{Characteristics of carbon emissions}

According to Eq.1, the carbon emission of Shanxi province is shown in Figure 1. As can be seen from Figure 1, Shanxi's carbon emissions in 1990 were 26.57 million tons, increasing to 73.27 million tons in 2017, an increase of almost two times. The carbon emissions are in the trend of increasing year by year. The growth rate of carbon emissions in the study cycle can be divided into three stages: from 1991 to 1996, the overall carbon emissions in Shanxi Province showed an upward trend, but the growth was slow; from 1997 to 2005, there was a short-term fluctuation in carbon emissions, 
but the overall trend was upward; after 2005, the total carbon emissions entered a linear upward state, in the following year, carbon emissions entered a fluctuation period again.

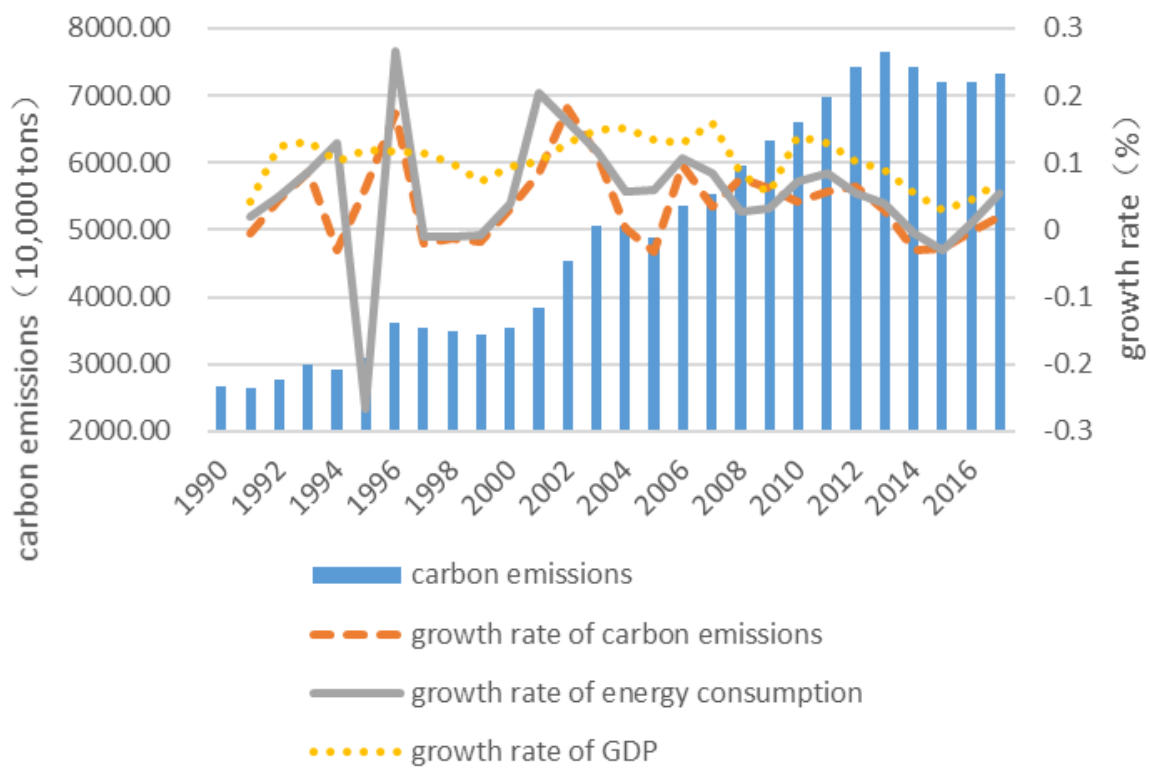

Figure 1. The carbon emission, energy consumption and GDP output in Shanxi province in 1990-2017

From 1990 to 2017, the carbon emissions of Shanxi Province basically kept pace with the growth of energy consumption. There was a sudden change in energy consumption in 1995 because an adjustment was made in statistical caliber in this year. From 2000 to 2003, the growth rate of carbon emissions was slightly faster than the growth rate of gross domestic product. After that, with the evolution of energy consumption structure and industrial structure in Shanxi province, the total carbon emissions are increasing, but the growth rate is slowing down. The growth rate of GDP has begun to be slightly faster than the growth rate of carbon emissions (as in Fig 1).

\section{Analysis of evolution characteristics of carbon emissions}

Existing research on the growth factors of carbon emissions mainly focuses on population, economic growth, industrial structure, energy structure. In this paper, the author does not focus on the analysis of factors affecting the growth of carbon emissions, so she quoted the existing research conclusions (He, 2012; Tong et al., 2015; Ren, 2015; Chen et al., 2016). The academic community has reached a consensus on the role of population in promoting carbon emissions, so the author will not repeat it.

\section{Analysis on the relationship between economic growth and carbon emissions evolution}

In order to investigate the quantitative relationship between economic growth and carbon emissions, we use the commonly used environmental Kuznets curve to analyze.

$$
c=\beta_{0}+\beta_{1} y+\beta_{2} y^{2}+\beta_{3} y^{3}+u_{i}
$$


In the equation (2), $\mathrm{c}$ is the carbon emissions over years, $\mathrm{y}$ is GDP per capita over years (The data are derived from the statistical yearbook of Shanxi province. The year 1952 is used as the benchmark year to calculate the reduction). Regression results are obtained by using Eviews8, as shown in Table 1.

Table 1. The regression results of carbon emissions and economic growth in Shanxi province

\begin{tabular}{|c|c|c|c|}
\hline Parameters & $\begin{array}{c}\text { Model 1 } \\
c=\beta_{0}+\beta_{1} y+\mu\end{array}$ & $\begin{array}{c}\text { Model 2 } \\
c=\beta_{0}+\beta_{1} y+\beta_{2} y^{2}+\mu\end{array}$ & $\begin{array}{c}\text { Model 3 } \\
\mathrm{c}=\beta_{0}+\beta_{1} y+\beta_{2} y^{2}+\beta_{3} y^{3}+u_{i}\end{array}$ \\
\hline$\beta_{0}$ & $\begin{array}{c}2276.179 \\
(22.98478)\end{array}$ & $\begin{array}{c}1847.739 \\
(-12.46559)\end{array}$ & $\begin{array}{c}1534.06 \\
(-5.535005)\end{array}$ \\
\hline$\beta_{1}$ & $\begin{array}{c}0.902713 \\
(-28.01651) \\
\end{array}$ & $\begin{array}{c}1.297577 \\
(-11.05064)\end{array}$ & $\begin{array}{c}1.738635 \\
(-4.952082) \\
\end{array}$ \\
\hline$\beta_{2}$ & & $\begin{array}{c}-6.14 \mathrm{E}-05 \\
(-3.450783) \\
\end{array}$ & $\begin{array}{c}-0.000217 \\
(-1.835032) \\
\end{array}$ \\
\hline$\beta_{3}$ & & & $\begin{array}{c}1.53 \mathrm{E}-08 \\
(-1.330053) \\
\end{array}$ \\
\hline adjusted $\mathrm{R}^{2}$ & 0.971497 & 0.980945 & 0.981618 \\
\hline F-statistics & 784.9247 & 593.0045 & 410.4036 \\
\hline
\end{tabular}

Note: The test value of $\mathrm{t}$ statistics for each parameter are in brackets

Regression results show that the three models can effectively fit the relationship between carbon emissions and economic growth, but the parameters are significantly different. The fitting effect of model three is the best, below 5\% level. The constant term and the linear term of per capita GDP are checked by significance test and it shows that between 1990 and 2013, there is a monotonic trend between carbon emissions and economic growth in Shanxi Province, the corresponding increase of carbon emissions is $1.74 \%$ for every $1 \%$ economic growth.

\section{Analysis on the relationship between industrial structure evolution and carbon emissions}

\section{Method of calculating the diversity coefficient of industrial structure}

The evolution of carbon emissions is not only related to economic growth, but also to industrial structure. In the existing studies, most of the measurement of the impact of industrial structure on carbon emissions is based on the industrial structure diversification coefficient proposed by Zhang et al. (2010) and Huang (2014). This coefficient is representative and reasonable to a certain extent, and can effectively show the proportion of the secondary and tertiary industries in the economic structure, but also has certain limitations. Because this coefficient is based on the primary industry as a benchmark, if the proportion of the primary industry in the economic structure is reduced, the coefficient will increase with the proportion of the primary industry decreasing, while the adjustment coefficient between the secondary industry and the tertiary industry can not be reflected. Therefore, the author used industrial structure correction coefficient from Huang (2014) to analyze the relationship between industrial structure and carbon emissions.

In order to quantitatively measure the impact of industrial structure on the evolution of carbon emissions, the author constructed an environmental-quality regression equation between carbon emissions and industrial structure diversification coefficient by using the industrial structure diversification coefficient. 
The construction method of industrial structure coefficient is to use A (agriculture), I (industry), S (service) to represent the output value of the first, second and third industry respectively, and $\mathrm{D}$ to represent the diversification coefficient of industrial structure. Then:

$$
I S F=\sum\left(\frac{A}{A}, \frac{I}{A}, \frac{S}{A}\right)
$$

According to the relevant data of Shanxi Statistical Yearbook, the industrial structure diversification coefficient of Shanxi Province from 1990 to 2017 was calculated by equation (3). The output value is calculated on the basis of the year of 1952 as the following Figure 2.

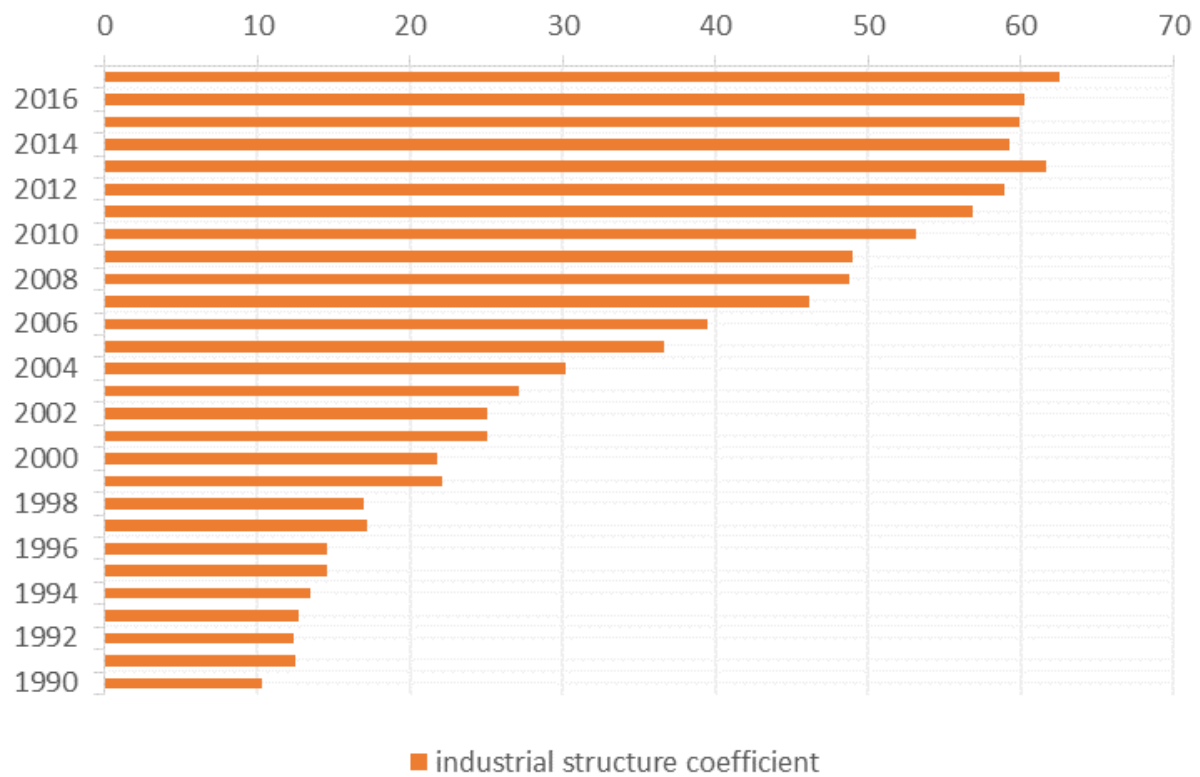

Figure 2. Industrial structure diversification coefficient of Shanxi province 1990-2017

From Figure 2 we can find that, the diversification coefficient of Shanxi province industrial structure basically showed a linear upward trend in the research stage.

\section{Regression result of industrial structure diversification coefficient and carbon emissions}

In order to investigate the role of industrial structure change in the evolution process of carbon emissions in Shanxi Province, the regression equation of industrial structure evolution coefficient and carbon emissions was established by using the EnvironmentQuality equation:

$$
c=\beta_{0}+\beta_{1} y+\beta_{2} y^{2}+\beta_{3} y^{3}+u_{i}
$$

The parameters were estimated by stepwise changing the curve form by Eq. 4, and the regression results are shown in Table 2.

From the regression results of Table 2, we can see that the fitting result of Model 3 is the best, which reflects the characteristics between the evolution of industrial structure 
and carbon emissions. From 1990 to 2017, there is an inverted U-shaped curve between carbon emissions and the coefficient of industrial structure diversification in Shanxi Province. When the coefficient of industrial structure diversification is 25.08 , the turning point of the curve corresponding to the time axis between 2002 and 2003 appears. That is, when the diversity coefficient of industrial structure is less than 25.8, the evolution of industrial structure brings about an increase in carbon emissions.

Table 2. The regression results of carbon emissions and industrial structure diversity coefficient in Shanxi province

\begin{tabular}{|c|c|c|c|}
\hline Parameters & $\begin{array}{c}\text { Model 1 } \\
c=\beta_{0}+\beta_{1} y+\mu\end{array}$ & $\begin{array}{c}\text { Model 2 } \\
c=\beta_{0}+\beta_{1} y+\beta_{2} y^{2}+\mu\end{array}$ & $\begin{array}{c}\text { Model 3 } \\
\mathrm{c}=\beta_{0}+\beta_{1} y+\beta_{2} y^{2}+\beta_{3} y^{3}+u_{i}\end{array}$ \\
\hline$\beta_{0}$ & $\begin{array}{c}1819.606 \\
(13.6308)\end{array}$ & $\begin{array}{c}1807.974 \\
(5.638141)\end{array}$ & $\begin{array}{c}554.082 \\
(0.823589)\end{array}$ \\
\hline$\beta_{1}$ & $\begin{array}{c}91.27689 \\
(23.67227)\end{array}$ & $\begin{array}{c}92.17266 \\
(4.062833)\end{array}$ & $\begin{array}{c}238.2008 \\
(3.247835)\end{array}$ \\
\hline$\beta_{2}$ & & $\begin{array}{c}-0.012914 \\
(-0.040096) \\
\end{array}$ & $\begin{array}{c}-4.749545 \\
(-2.066715) \\
\end{array}$ \\
\hline$\beta_{3}$ & & & $\begin{array}{c}0.044947 \\
(2.078798)\end{array}$ \\
\hline adjusted $\mathrm{R}^{2}$ & 0.960507 & 0.958629 & 0.964279 \\
\hline F-statistics & 560.3766 & 267.4737 & 207.9591 \\
\hline
\end{tabular}

Note: The test value of $\mathrm{t}$ statistics for each parameter are in brackets

When the coefficient of industrial structure diversification is greater than 25.8, the evolution of industrial structure can promote the reduction of carbon emissions. This coincides with the results of carbon emission growth rate and industrial output value growth rate in Figure 2, indicating that the industrial restructuring policy of Shanxi Province has achieved initial effect.

\section{Analysis of the relationship between energy consumption structure and carbon emissions evolution}

The energy structure of a country or region will change with the development of economy, from unification to diversification. In order to measure this change, this author constructed a pluralistic model of energy structure. F (first) denotes the dominant energy consumption in the economic development of a country or region, $\mathrm{S}$ (second), $\mathrm{T}$ (third) ... denotes the subsequent energy consumption, and ESF denotes the coefficient of energy structure diversification in Eq. 5.

$$
E S F=\sum\left(\frac{F}{F}, \frac{S}{F}, \frac{T}{F}\right)
$$

From 1990 to 2017, coal has been the dominant energy consumption type in Shanxi Province. Therefore, coal was selected as unitary element in the evolution of energy structure, and other energy types as pluralistic elements of energy consumption structure. So the diversification coefficient of consumption structure in Shanxi province is as follow:

$$
E S F=\sum\left(\frac{\sigma}{6}, \frac{0}{\sigma}, \frac{e}{6}, \frac{g}{c}\right)
$$


In the equation (6) c,o,e,g represents energy consumption of coal, oil, electricity, natural gas and other gases, respectively.

According to equation (6) and the data of Shanxi Statistical Yearbook, we calculated the coefficient of energy structure diversification, such as Table 3.

Table 3. The consumption structure diversification coefficient of Shanxi province in 19902017

\begin{tabular}{cccc}
\hline Year & Coefficient & Year & Coefficient \\
\hline 1990 & 1.632569 & 2004 & 1.727133 \\
1991 & 1.69738 & 2005 & 2.059616 \\
1992 & 1.709464 & 2006 & 2.105542 \\
1993 & 1.732847 & 2007 & 2.204329 \\
1994 & 1.280864 & 2008 & 2.122848 \\
1995 & 1.287026 & 2009 & 2.08718 \\
1996 & 1.596045 & 2010 & 2.143757 \\
1997 & 1.63661 & 2011 & 2.194854 \\
1998 & 1.642659 & 2012 & 2.149954 \\
1999 & 1.67804 & 2013 & 2.181708 \\
2000 & 1.688116 & 2014 & 2.469229 \\
2001 & 1.604971 & 2015 & 2.498509 \\
2002 & 1.567656 & 2016 & 2.506846 \\
2003 & 1.569563 & 2017 & 2.664153 \\
\hline
\end{tabular}

From Table 3, we can see that Shanxi Province's energy consumption structure diversification coefficient rose slowly, from 1990 to 2017, it increased by about 1.0, the entire evolution process shows certain phased features. (1) The rising stage from 1990 to 1995. At this stage, the structure of energy consumption is basically on the rise stage, and in very few years, the energy structure has regressed. It shows that the energy consumption structure in this stage has been improved to a certain extent, and the energy structure adjustment policies in Shanxi Province have achieved certain results. The proportion of electricity in the structure of energy consumption is gradually increasing. (2) From 1996 to 2004, the stage of rebound decline. Affected by the Asian financial crisis, in order to stimulate economic development, some of the small coal kilns shut down have been rekindled, and some of the high energy consumption projects have been restarted, resulting in a re-increase in coal consumption, a decline in energy structure coefficient, and a return to the development model relying on coal consumption. (3) The slow recovery stage from 2005 to 2017. At this stage, Shanxi's industrialization was developing rapidly, urbanization was steadily advancing, and energy consumption had undergone some new changes. At the same time, the government of Shanxi Province decided to change the economic structure of "the coal dominant" and put forward the "coal-based, multi-development" strategy. The consumption of electricity and natural gas increased steadily, and the diversification coefficient of energy structure increased steadily (Xu, 2014).

In order to investigate the role of energy structure change in the evolution process of carbon emissions in Shanxi Province, this section still adopts the regression analysis of environmental quality curve. The regression equation is the same as equation 4, but the $\mathrm{Y}$ in the equation is expressed as the coefficient of energy structure diversification in this section. Model regression estimates are shown in Table 4. 
Table 4. the regression results of carbon emissions and energy structure diversity coefficient in Shanxi province

\begin{tabular}{c|c|c|c}
\hline \multirow{2}{*}{ Parameters } & $\begin{array}{c}\text { Model 1 } \\
c=\beta_{0}+\beta_{1} y+\mu\end{array}$ & $\begin{array}{c}\text { Model 2 } \\
c=\beta_{0}+\beta_{1} y+\beta_{2} y^{2}+\mu\end{array}$ & $\begin{array}{c}\text { Model 3 } \\
\mathrm{c}=\beta_{0}+\beta_{1} y+\beta_{2} y^{2}+\beta_{3} y^{3}+u_{i}\end{array}$ \\
\hline$\beta_{0}$ & $\begin{array}{c}-3639.798 \\
(-2.952779)\end{array}$ & $\begin{array}{c}14304.97 \\
(0.0677)\end{array}$ & $\begin{array}{c}-63060.86 \\
(-1.00861)\end{array}$ \\
\hline$\beta_{1}$ & $\begin{array}{c}4557.069 \\
(6.7509)\end{array}$ & $\begin{array}{c}-15796.35 \\
(0.0724)\end{array}$ & $\begin{array}{c}125231.2 \\
(1.10351)\end{array}$ \\
\hline$\beta_{2}$ & & 5630.887 & $-1.163631)$ \\
$\left(\beta_{3}\right.$ & & & 16342.16 \\
$(2.444072)$ & $0.72460)$ \\
\hline adjusted $\mathrm{R}^{2}$ & 0.659636 & 0.722393 & 21.67697 \\
\hline F-statistics & 45.57465 & 30.92554 & \\
\hline
\end{tabular}

Note: The test value of $\mathrm{t}$ statistics for each parameter are in brackets

The regression results showed that the adjusted $\mathrm{R}^{2}$ of the third model is the maximum among the three models. However, at the 5\% significance level, the parameters of the model are not significant, only the parameters of model 1 are significant at the 5\% level and its adjusted number is only 0.66 , indicating that between 1990 and 2017, there was no simple linear relationship between the diversity coefficient of energy consumption structure and carbon emissions in Shanxi Province. There was a more complex relationship between energy consumption structure evolution and carbon emissions growth, which needs further discussion. This is similar to the result of the relationship between the diversification coefficient of China's energy consumption structure and carbon emissions calculated by Zhang (2003) and Li and Cui (2011).

\section{Conclusion}

Based on the time series data from 1990 to 2017, the author selected Shanxi Province as the representative of energy-intensive provinces, empirically analyzed the changing characteristics of carbon emissions and carbon emissions intensity in energy-intensive provinces. Using environmental Kuznets curve, environmental-quality equation, and with the help of the constructed industrial structure diversification coefficient, energy structure diversification coefficient, the author examined the role of economic growth, industrial restructuring, energy consumption structure changes in the evolution of carbon emissions. The conclusions are as follows:

1) From 1990 to 2017, the carbon emissions of Shanxi Province in general were in the state of growth, but the increase rate was different.

2) Economic growth has a direct pull on the growth of carbon emissions, and every $1 \%$ increase in economic growth, carbon emissions will increase accordingly.

3) Industrial evolution is a bi-directional pulling factor of carbon emissions growth: When the industrial structure transits from the primary industry to the secondary industry, the industrial structure evolution has a pulling effect on carbon emissions growth. When the industrial structure transits from the secondary industry to the tertiary industry, the industrial structure reduces the growth of carbon emissions, showing the characteristics of inverted U-shaped curve. Before 
2003, there was an inflection point between the relationship of industrial structure diversification coefficient and carbon emissions.

4) The linear relationship between the evolution of energy structure and carbon emissions is not obvious. There is no inverted U-shaped curve between energy consumption and carbon emissions in Shanxi Province. This shows that the rebound effect of energy consumption may occur in the evolution process of energy structure in Shanxi Province, which needs further discussion.

At present, most studies believe that to control the growth of carbon emissions is to control the population, adjust the industrial structure, adjust the energy structure, and increase the proportion of non-mineral resource in energy consumption. Among the measures, which measures are more effective for carbon emission reduction in energy intensive provinces? The liberalization of the single second child policy in 2013 did not cause a small peak in fertility, and the implementation of the national family planning policy over the past few decades has changed people's conception of fertility. This shows that the policy effect of controlling population growth to reduce carbon emissions will not be significant for some time to come. From the perspective of energy consumption structure, Shanxi Province is a big province of coal production and consumption, although the energy structure reform has been carried out, but the coalbased energy consumption structure cannot be rapidly changed in a short time. At the same time, with the industrialization and urbanization process of Shanxi Province, the demand for primary energy will increase. The regression results also show that the linear relationship between the evolution of energy consumption structure and carbon emissions is not very obvious, and the potential to reduce carbon emissions through the evolution of energy structure is very small. The most effective policy to reduce carbon emissions in Shanxi is industrial restructuring. In the future, we need to continue to promote industrial restructuring, from the secondary industry to the tertiary industry. At the same time, in order to promote the transformation of high energy-consuming sectors in the secondary industry to low energy-consuming sectors, the support of technological progress is also needed in the process of transformation. To sum up, the main potential of carbon emission reduction in energy-intensive provinces lies in the rational evolution of industrial structure and technological progress, at the same time, ensuring that the population does not soar, the energy structure retrogression or reasonable evolution.

Acknowledgements. The authors gratefully acknowledge the financial support from Shanxi Datong University PhD Start-up Foundation (2014-b-16), Datong Soft Science Foundation (2017151), Shanxi Province Philosophy and Social Science Planning Foundation, Shanxi Province Soft Science Foundation (2018041067-4), Shanxi Province Soft Science Foundation (2018041060-7) and West Program of the National Social Science Fund of China (No. 15XGL018).

\section{REFERENCES}

[1] Chen, S. F., Liu, Y., Zou, X. P. (2012): A Theoretical and empirical study on Driving Forces of Carbon Dioxide Emissions Evolution. - Scientific Management Research 1: 43-48.

[2] Chen, J. L., Li, P. X., Gao, J. L. (2016): Spatiotemporal patterns and influencing factors of carbon emissions in the Pan-Yangtze River Delta region, 1990-2014. - Progress in Geography 12: 1472-1482.

[3] Chi, Q.-S. (2007): Forecasting the Increase of Petroleum Consumption in China based on the ARIMA Model. - Resources Science 5: 69-73. 
[4] China National Development and Reform Commission (2012): The Second National Information Circular on Climate Change of the People's Republic of China.

[5] Gao, B. (2017): The Empirical Study on the Relationship Between Energy Consumption, Carbon Emissions and Economic Growth in Beijing - Tianjin - Hebei. - Journal of Industrial Technological \& Economics: 82-92.

[6] Gao, B., Fang, J., Lu, X. (2017): Evolution relationship between agricultural carbon emissions and economic growth and its reduction potential. - Journal of Arid Land Resources and Environment: 13-18.

[7] He, H. B. (2012): Factors Analysis of Influencing China's Carbon Emissions. - Huazhong University of Science and Technology.

[8] Hu, Y., Liu, J.-F., Hu, W. (2016): Regional Variance, Trend Evolution and Factors of China's Carbon Emission Intensity Based on 30 Provinces (Cities and Districts)' 19972012 panel data. - Resources \& Industries: 7-13.

[9] Huang, R., Zhe, Y., Wang, Z. (2010): Prediction on Shanghai's Energy Consumption Trend and Carbon Emission Pink. - Shanghai Journal of Economics 4: 81-90.

[10] Huang, H. (2014): Research on the Pertinence Between Shanghai's Economic Polynary Structure and Carbon Emission. - China Population, Resources and Environment: 32-35.

[11] Li, Z. H., Cui, Y. A. (2011): An Empirical Study on the Evolution Characteristics of China's Carbon Emissions. - Statistics \& Decision: 122-126.

[12] Li, J.-B. Huang, X.-J., Wu, C.-Y. (2015): Analysis of Spatial Heterogeneity Impact Factors on Carbon Emissions in China. - Economic Geography 11: 21-28.

[13] Liang, H.-M., Li, H.-L. (2014): Evolution Characteristics of Carbon Emissions and Its Influencing Factors in Circum-Bohai Sea Region. - Journal of Beihua University (Natural Science): 274-280.

[14] Lin, B., Liu, X. (2010): China's Carbon Dioxide Emissions under the Urbanization Process: Influence Factors and Abatement Policies. - Economic Research Journal 8: 2030.

[15] Lin. B., Huang, X. G. (2011): The Evolution Trend of China's Regional Carbon Emissions under Gradient Development Mode__Based on the Perspective of Spatial Analysis. - Journal of Financial Research 12: 35-46.

[16] Liu, J. C. (2011): Energy Saving Potential and Carbon Emissions Prediction for the Transportation Sector in China. - Resources Science 4: 640-646.

[17] Liu, H., Bao, Z., Yang, Q. (2013): Distributional Dynamic and Evolution of China's CO2 Emissions. - Resources Science 4: 1925-1932.

[18] Ma, D., Wu, W., Dong, Z. (2017): Industrial Carbon Emission Performance and Its Influencing Factors in China: Based on an Empirical Study of Spatial Panel Data Model. - China Economic Studies 1: 121-135.

[19] Mirzaei, M., Bekri, M. (2017): Energy Consumption and CO2 Emissions in Iran, 2025. Environmental Research: 345-351.

[20] Qi, S. Z., Lin, S., Wang, B.-B. (2015): Impact of Economic Growth Pattern of the Six Provinces of Central China on Regional Carbon Emission:Based on the Tapio Model and Lag Instrumental Variable Analysis of Panel Data. - China Population Resources and Environment 5: 59-66.

[21] Ren, J. (2015): Reviews on Carbon Emission Factors. - Resources \& Industries: 79-83.

[22] Song, D., Xu, A. (2011): Regional Difference and Influencing factors of China's Urban Carbon Emissions. - China Population, Resources and Environment 11: 8-14.

[23] Song, J. (2012): Factor Decomposition of Carbon Emissions from Energy Consumption of Shandong Province Based on LMDI. - Resources Science: 35-41.

[24] Sun, X. M., Zhou, M., Qi, Z.-F. (2011): Empirical Study on Evolution Characteristics and Factors of Carbon Emissions in Shandong Province. - East China Economic Management 7: 11-15. 
[25] Tian, Y., Zhang, J.-B., Yin, C.-J., (2014): Distributional Dynamics and Trend Evolution of China's Agricultural Carbon Emissions-An Analysis on Panel Data of 31 Provinces from 2002 to 2011. - Population, Resources and Environment 7: 91-98.

[26] Tong, X., Chen, K., Li, G. (2015): An Empirical Study of Chinese Carbon Emissions and Influencing Factors-Grey Correlation Analysis of China and 30 Provincial between 2000 and 2011. - Journal of Industrial Technological Economics: 66-78.

[27] Wang, C.-K., Xie, H. Z. (2015): Study on Dynamic Characteristics and Influencing Factors of China's Power Carbon Emissions. - China Population, Resources and Environment 4: 21-27.

[28] Wang, R., Jiang, Z. (2017): Energy Consumption in China's Rural Areas: A Study Based On the Village Energy Survey. - Journal of Cleaner Production: 452-461.

[29] Wu, X. R., Zhang, J. (2014): Provincial Agricultural Carbon Emissions in China: Calculation, Performance Change and Influencing Factors. - Resources Science 4: 129138.

[30] Xu, L., Zhao, T., Yang, X. F. (2013): Study on Driving Forces of Resource Provinces' Carbon Emissions-Based On the PATH-STIR PAT Model. - Forum on Science and Technology in China 12: 52-58.

[31] Xu, L. (2014): Analysis of Influence Factors and Prediction of Carbon Emissions during the Process of Urbanization in Shanxi Province. - Tianjin University.

[32] Yuan, C. W., Zhang, S., Jiao, P. (2017): Temporal and spatial variation and influencing factors research on total factor efficiency for transportation carbon emissions in China. Resources Science 4: 687-697.

[33] Zhang, L. (2003): Economic Development and Its Bearing on CO2 Emission. - Acta Geographica Sinica: 629-637.

[34] Zhang, L., Huang, Y., Li, Y. (2010): An Investigation on Spatial Changing Pattern of CO2 Emissions in China. - Resources Science: 211-217.

[35] Zhao, Z. Y., Yang, C.-F. (2012): Decomposition analysis of China's carbon emission driving factors. - China Soft Science 6: 175-183.

[36] Zhou, K., Mao, Y.-Y. (2017): Research on the factors of implied carbon export in China: based on the analysis of counter factual method. - China Population, Resources and Environment 6: 16-26. 